\title{
COMPARATIVE STUDY BETWEEN PROPULSION CONTROL SYSTEM FAILURES OF AN ELECTRICAL VEHICLE PILOTED BY FOC AND BY DTC USING DUAL-INDUCTION-MOTORS STRUCTURE
}

\author{
Salah YAHIA CHERIF ${ }^{1 *}$, Djamel BENOUDJIT ${ }^{1,2}$, Mohamed Said NAIT-SAID ${ }^{1}$, \\ Nasreddine NAIT-SAID ${ }^{1}$ \\ ${ }^{1}$ LSP-IE'2000 Laboratory, Electrical Engineering department, University of Batna 2, 05000, Batna - Algeria, \\ ${ }^{2}$ Health and Safety Institute, University of Batna 2, 53 route de Constantine, 05078, Batna - Algeria \\ *s.yahiacherif@univ-batna2.dz
}

\begin{abstract}
This paper deals with a comparative study using numerical simulations between the failures effect caused by the speed sensor faults for a propulsion control system (PCS) of an electrical vehicle (EV) using dualinduction motors structure. The PCS strategies are achieved on two types of controls where the first one is done from a flux-oriented control (FOC) and the second one is conducted from a direct torque control (DTC). For an electric vehicle, we will often guarantee service continuity, in spite of the occurred faults such as an offset fault in speed sensor and a zero-feedback sensor speed fault which both are essentially needed in the structure of the PCS-EV. The occurred fault cited above might influence one of the dual induction motors which could be conducted an unbalance in the dual used motors and from which the control of the vehicle might be also lost. The results of the realized numerical simulations on the EV conducted by the PCS demonstrate clearly the impact of the so-called-fault. Thereafter, we can also appreciate the robustness using each used control propulsion system in despite of the occurred speed sensor fault.
\end{abstract}

Keywords: Electrical Vehicle (EV), Propulsion Control System (PCS), Flux Oriented Control (FOC), Direct Torque Control (DTC), Speed sensor offset and Zero-feedback faults.

\section{INTRODUCTION}

The demand for alternative energy sources to reduce $\mathrm{CO} 2$ emission is one of the greatest challenges nowadays [1]. Electric vehicle offers the most promising solution to reduce vehicular emissions [2]. The principle of an electric vehicle $(\mathrm{EV})$ operation is converting electricity to mechanical energy by the electrical motors, such induction motors. The conventional mechanical structures using reduction gears and mechanical differential can raise the weight of the EV and could cause in greater energy consumption. The alternative solution was to replace it with a propulsion control system (PCS) using an electric differential system assured by dual motors operating at different speeds. For control of the propulsion system we use two types of robust control, flux-oriented control (FOC) and direct torque control (DTC). Among these two used controls, each of them presents its advantages and its drawbacks from the point of view of implementation and performance. In this case, by a comparative study when the speed sensor faults are occurred, we would be able to derive the advantage of one control over the other in terms of performance and robustness of which this electrical differential ultimately depends on it.
Since the faults will be occurred, the PCS failure, so the performances of $\mathrm{EV}$, decrease and it can reach a loss of the control. The control of propulsion system is predisposed to many faults, which may affect the system performance. Concerning speed sensor faults, we can consider both faults as follows:

- offset fault (measurement offset).

- zero feedback fault (no feedback information).

The paper is organized as follows. Sections 2 and 3 presents both controls of the induction motor used for the PCS whereas concern successively the field-oriented control and the direct torque control. Dual-motor structure of the proposed PCS is shown in section 4. Speed sensor faults are presented in section 5. Section 6 exposes the effected simulations results. The conclusion is done in section 7 .

\section{FILED-ORIENTED CONTROL (FOC)}

The well-known field orientation control (FOC) strategy provides a linear and decoupled control between the flux and torque of an induction machines.

Then the rotor flux orientation process is given by the imposed zero constraints of quadrate rotor flux component [3]. 
The induction motor model after flux orientation is given as follows in its conventional nomenclature indicated above.

$$
\begin{gathered}
v_{s d}=\left(R_{s} i_{s d}+\sigma L_{s} \frac{d i_{s d}}{d t}\right)+e_{q} \\
v_{s q}=\left(R_{s} i_{s q}+\sigma L_{s} \frac{d i_{s q}}{d t}\right)+e_{d} \\
\phi_{r q}=0 \text { and } \phi_{r d}=\phi_{r} \\
e_{d}=\omega_{s}\left(\sigma L_{s} i_{s d}+\frac{M}{L_{r}} \phi_{r}\right) \\
e_{q}=\frac{M}{L_{r}} \frac{d \phi_{r}}{d t}-\sigma L_{s} \omega_{s} \\
\phi_{r}=\frac{M}{1+T_{r} s} i_{s d} \\
\theta_{s}=\int\left(\omega_{s}+p \Omega\right) d t \\
T_{e}=p \frac{M}{L_{r}} \phi_{r d} i_{s q}
\end{gathered}
$$

Figure 1 shows a general block diagram implementation of FOC on an induction motor. Torque and rotor flux are controlled indirectly by stator current components $i_{s d}, i_{s q}$ (direct and quadrate) respectively.

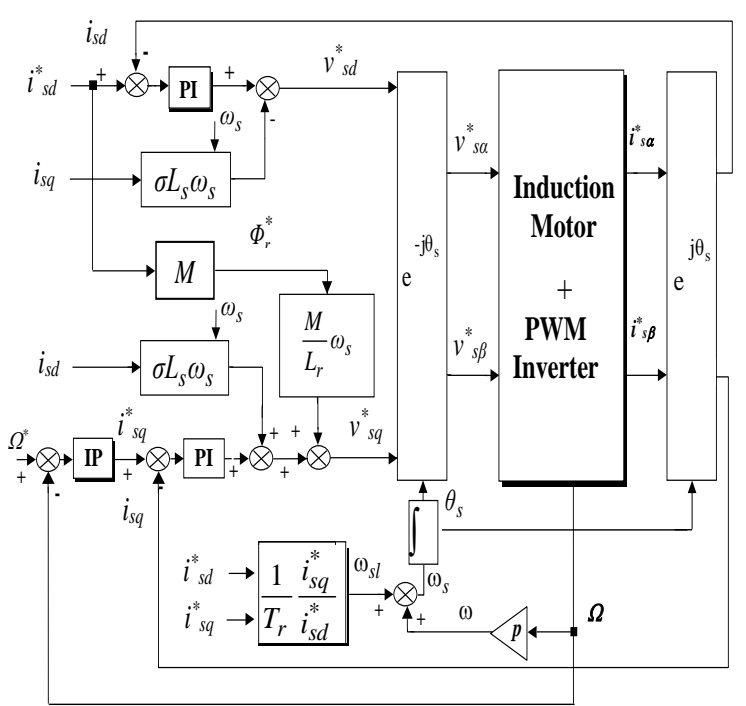

Fig. 1. Block diagram implementation of FOC-IM

\section{DIRECT TORQUE CONTROL (DTC)}

The direct torque control of induction motor, assumed as one of the high-performance control systems not needed a transformation rotation, consists of estimators, hysteresis comparators for electromagnetic torque, stator flux and an optimal switching table [4][5].

The stator flux components equations in stationary reference frame are given by

$$
\left\{\begin{array}{l}
\phi_{s \alpha}=\int_{0}^{t}\left(v_{s \alpha}-R_{s} i_{s \alpha}\right) d t \\
\phi_{s \beta}=\int_{0}^{t}\left(v_{s \beta}-R_{s} i_{s \beta}\right) d t
\end{array}\right.
$$

The stator current is described by the complex form:

$$
i_{s}=i_{s \alpha}+j i_{s \beta}
$$

The location of the estimated flux is defined as:

$$
\theta=\operatorname{Arctan}\left(\frac{\phi_{s} \beta}{\phi_{s \alpha}}\right)
$$

The torque of induction motor is given by the following relation:

$$
T_{e}=p\left(\phi_{s \alpha} i_{s \beta}-\phi_{s \beta} i_{s \alpha}\right)
$$

Figure 2 shows a general block diagram implementation of DTC-IM intended to EV application.

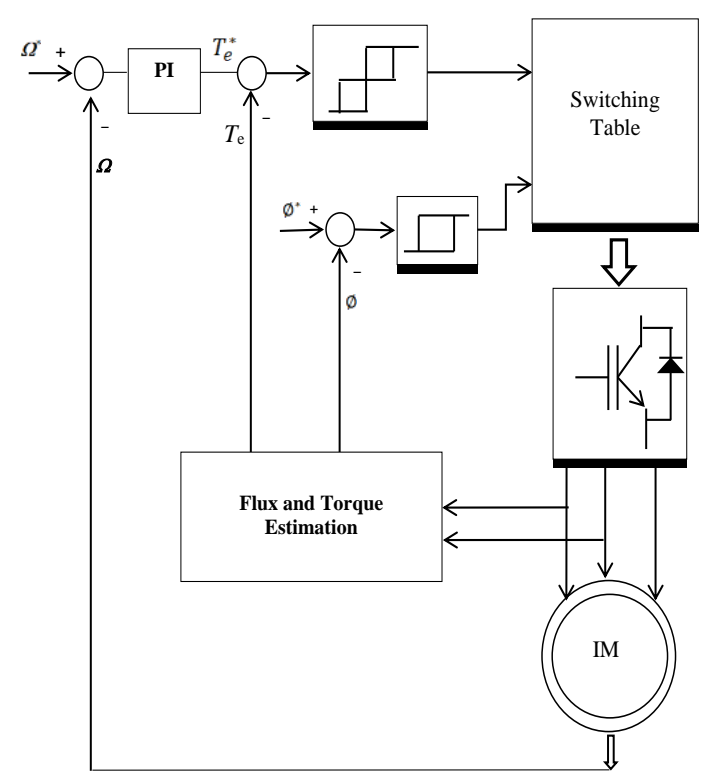

Fig. 2. Block diagram of DTC-IM

\section{PROPULSION CONTROL SYSTEM STRUCTURE}

For conventional vehicle, when a turn is reached, the speed difference of the rear wheels is regulated by a mechanical differential in order to avoid vehicle slipping. This differential allows one wheel to rotate more quickly than the other. Besides the mechanical means, the differential action of a PCS when cornering can be electrically provided by electric motors operating at different speeds [6][7]. Figure 3 presents the layout of the proposed propulsion control structure in which a dual induction motors are used for driving separately the rear wheels of the vehicle via fixed gearing.

For a direction order of the steering wheels complementary signals are transmitted to the motors through power converters verifying the following equations [6]:

$$
\left\{\begin{array}{l}
\Omega_{1}=\Omega_{0}+\Omega_{d i f f} \\
\Omega_{2}=\Omega_{0}-\Omega_{d i f f}
\end{array}\right.
$$

Therefore, from the system of equations (13) above, the speed difference $\Omega_{\text {diff }}$ and the vehicle speed $\Omega_{0}$ may be done simply by: 


$$
\left\{\begin{array}{c}
\Omega_{\text {diff }}=\frac{1}{2}\left(\Omega_{1}-\Omega_{2}\right) \\
\Omega_{0}=\frac{1}{2}\left(\Omega_{1}+\Omega_{2}\right)
\end{array}\right.
$$

Figure 4 illustrates the functional block-diagram of the proposed electric differential. During a vehicle turn, the inner wheel will rotate slower than the outer one. Then the PCS, placed at the rear wheels of the vehicle, propels electrically the vehicle and assures the required differential speed between the wheels according to Eq. (13).

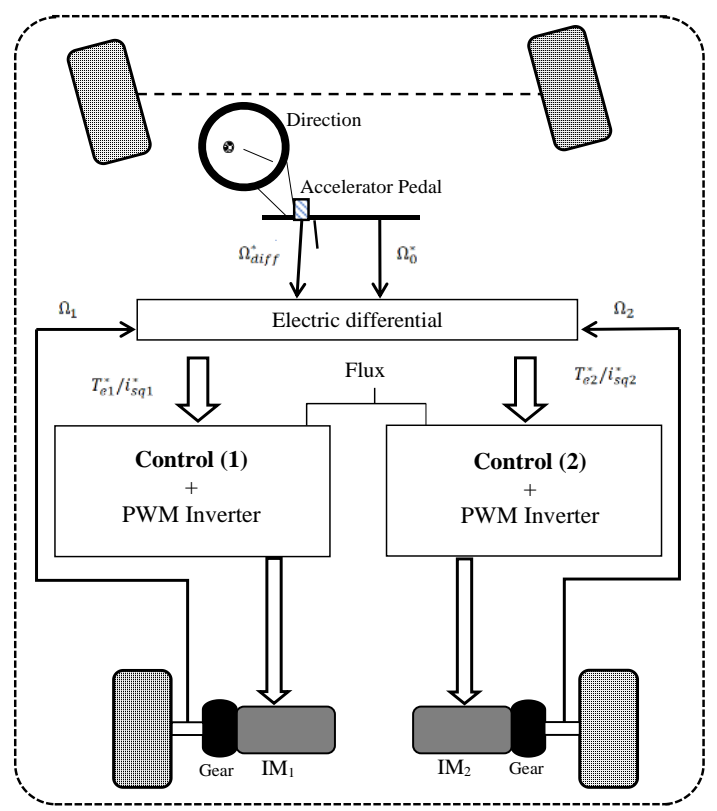

Fig. 3. Propulsion Control System Structure

The control speed is separately realized by the PIcontrollers for each induction motor and without a speed differential control loop. The vehicle speed $\Omega_{o}$ is not controlled but deduced from the motor'scontrolled speed $\Omega_{1}$ and $\Omega_{2}$. Also, as a result, using $s$-Laplace operator, we can write the following matrix relation:

$$
\left[\begin{array}{l}
\Omega_{1} \\
\Omega_{2}
\end{array}\right]=[F(s)]\left[\begin{array}{l}
\Omega_{1}^{*} \\
\Omega_{2}^{*}
\end{array}\right]
$$

with $[F(s)]=\operatorname{diag}\left(\left[F_{1}(s) F_{2}(s)\right]\right)$ and where $F_{1}(s)$ and $F_{2}(s)$ are the closed loop transfer functions. $\Omega_{1}^{*}$ and $\Omega_{2}^{*}$ indicate the input speed command for each motor. Theses transfer functions are done by:

$F_{i}=\frac{C_{i}(s) G_{i}(s)}{1+C_{i}(s) C_{i}(s)} \quad$ with $i=1$ or 2 indices corresponding to control (1) and (2) as mentioned in figure 3.

$G_{i}(s)$ is the open loop transfer function of the motor speed control acted by the input torque command mentioned by $T_{e i}^{*}$. Using the speed differential expression of Eq. (13), we can demonstrate that:

$$
\left[\begin{array}{c}
\Omega_{0} \\
\Omega_{\text {diff }}
\end{array}\right]=[\mathrm{H}]\left[\begin{array}{c}
\Omega_{0}^{*} \\
\Omega_{\text {diff }}^{*}
\end{array}\right]
$$

Where,

$[\mathrm{H}]=[\mathrm{P}]^{-1}[\mathrm{~F}(\mathrm{~s})][\mathrm{P}]=\frac{1}{2}\left[\begin{array}{ll}F_{1}(s)+F_{2}(s) & F_{1}(s)-F_{2}(s) \\ F_{1}(s)-F_{2}(s) & F_{1}(s)+F_{2}(s)\end{array}\right](17)$ with, $[P]=\left[\begin{array}{rr}1 & 1 \\ 1 & -1\end{array}\right]$.

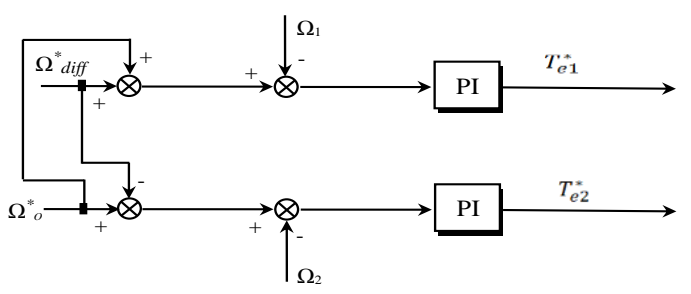

Fig. 4. Structure of Electric differential

Evidently, the decoupled control of differential speed is accomplished if and only if we have $F_{1}(\mathrm{~s})$ $=F_{2}(\mathrm{~s})$. This indicates that the two closed-loop controls of both motors must be identical else we cannot control, separately and in the same time, the differential speed $\Omega_{\text {diff }}$ and the vehicle speed $\Omega_{0}$. Therefore, the successfully reached control of the vehicle is obtained when the H-matrix is written as:

$$
\left[\begin{array}{c}
\Omega_{0} \\
\Omega_{d i f f}
\end{array}\right]=\left[\begin{array}{cc}
\frac{C_{1} G_{1}}{1+C_{1} G_{1}} & 0 \\
0 & \frac{C_{2} G_{2}}{1+C_{2} G_{2}}
\end{array}\right]\left[\begin{array}{c}
\Omega_{0}^{*} \\
\Omega_{\text {diff }}^{*}
\end{array}\right]
$$

\section{SPEED SENSOR FAULT}

There are three main kinds of faults in induction motor drive systems: electrical faults, mechanical faults, and sensor faults [8]. On the controller side, sensor faults are one of the most common problems in industrial applications [9]. In this paper we study two types of speed sensor faults presented below in the next subsections.

\subsection{Offset Sensor Speed Fault}

An offset fault means a perturbation caused by the difference between the real speed and its value measured by the sensor. This fault is simulated as shown in figure 5, by injecting a constant value to the real speed, so we can write that follows [10]:

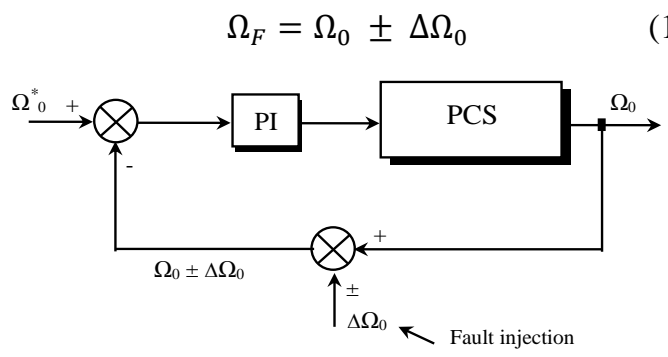

Fig. 5. Speed control block shame with offset sensor speed fault

\subsection{Zero Feedback Sensor Speed Fault}

This fault means that the sensor stops functioning and give no output signals. This occurs suddenly and in a very short time where " $\tau_{\text {Fault }}$ " is 
smaller than the mechanical time constant $\tau_{M e c}$, i.e " $\tau_{\text {Fault }}<\tau_{\text {Mec }}$ ". On Matlab, the simulation of this so-called zero feedback fault, illustated above by figure 6 , is simply done by multiplying the speed by zero [10][11].

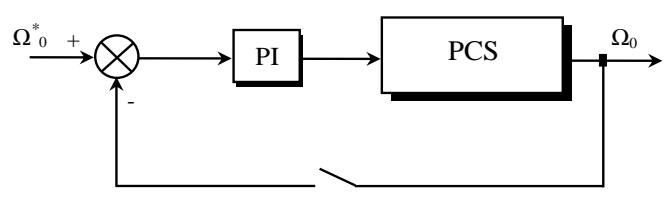

Fig. 6. Speed control block with zero feedback sensor speed fault

\section{SIMULATION RESULTS AND DISCUSSION}

To evaluate the performances and the failures effect caused by the speed sensor faults on the PCS$\mathrm{EV}$, simulations has been used from MATLAB/Simulink software package where rated data are given in appendix. Figures 7-12 (a, b, c) present and compare the main characteristics of the PCS-EV using dual-induction motors structure which are controlled by FOC and DTC schemes and where the fault speed sensor faults may be occurred: a) offset positive fault, b) offset negative fault and c) zero-feedback fault.

The obtained EV performances with the occurred sensor speed faults are illustrated in figures 7-8 and where the drawn dashed line showing the step reference speed from which the vehicle starts at $\mathrm{t}=0 \mathrm{~s}$ and continues to work during tests in despite to turning manoeuvres and occurred sensor speed faults. However, at $\mathrm{t}=3 \mathrm{~s}$, a load torque is applied on each motor. This last case might be occurred for example when EV wheels are stopped by a strong obstacle. After there, at $t=4 \mathrm{~s}$ the vehicle will turn right which results in the increase of the left wheel speed compared to the right one, i.e $\Omega_{\text {left }}>\Omega_{\text {Right }}$. This result proves the validity of the electric differential principle resulting from the proposed PCS when the vehicle accomplishes the turning maneuvers.

Then, to test severely the PCS-EV control performances, at $\mathrm{t}=7 \mathrm{~s}$ a speed sensor fault has been occurred.

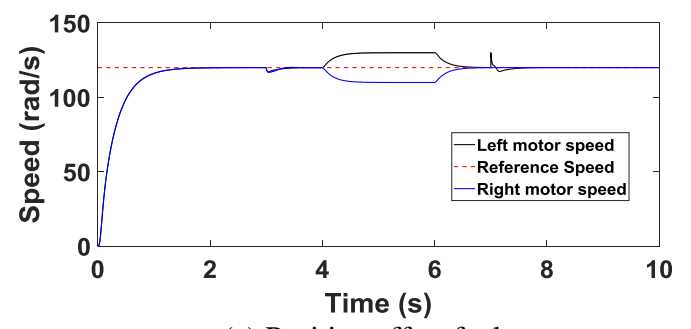

(a) Positive offset fault

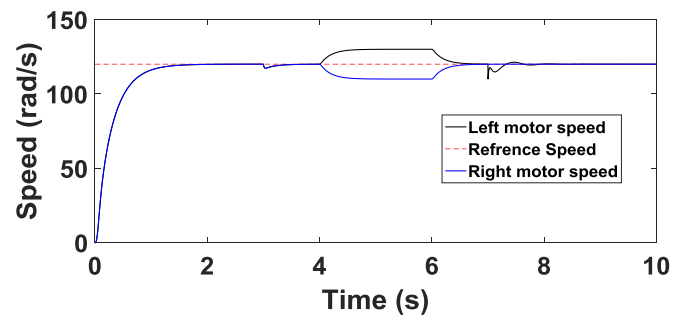

(b) Negative offset fault

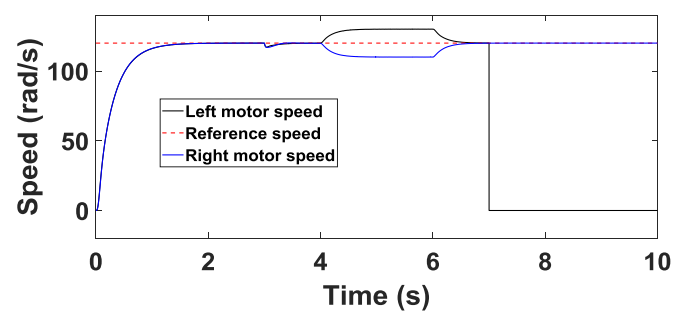

(c) Zero-feedback fault

Fig. 7. Speed-time of PCS-EV by FOC

It consists of a positive offset fault, negative offset fault and zero-feedback fault, which affect the speed sensor. After there, the vehicle continues directly its trajectory with a constant cruising speed until 10 seconds, which results in equality of the two motors speeds $\left(\Omega_{\text {Right }}=\Omega_{\text {left }}\right)$.

As we can see from figures $7 \mathrm{a}-\mathrm{b}$ and $8 \mathrm{a}-\mathrm{b}$, the control system reacts very well to the load perturbation and the reference trajectory is more tracked even in the presence of speed sensor faults. Contrary to this, for the zero-feedback fault (Figures 7c-8c) the vehicle leaves its reference trajectory, so the control of the differential action is gravely lost accompanied by the loss of the aim control vehicle direction.

Figures 9 and 10, both present with the same above tests, the variation of electromagnetic torque versus time according to the chosen speed direction of the vehicle. For the positive occurred offset sensor speed fault, we can see a big negative pic which affects the developed torque response on the FOC case, but with small impact on the DTC case. For the negative offset fault, the impact shows a similar precedent case, but with a positive torquepic.

Figures 11 and 12 illustrate and compare respectively the stator current responses versus time of one motor of the PCS-EV using FOC and DTC schemes. It can be seen that the current increases considerably for a FOC than in the DTC where it is noted a minimal impact.

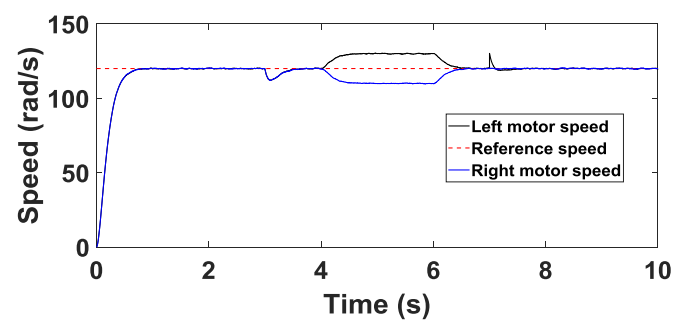

(a) Positive offset fault 


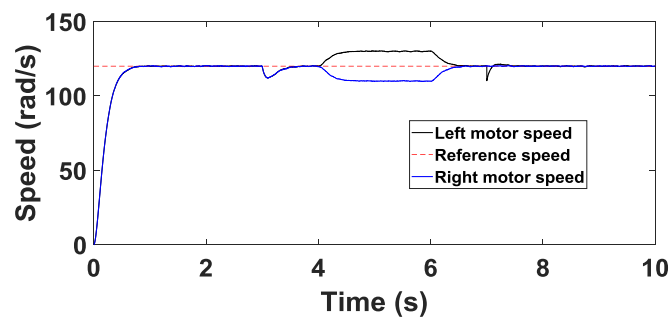

(b) Negative offset fault

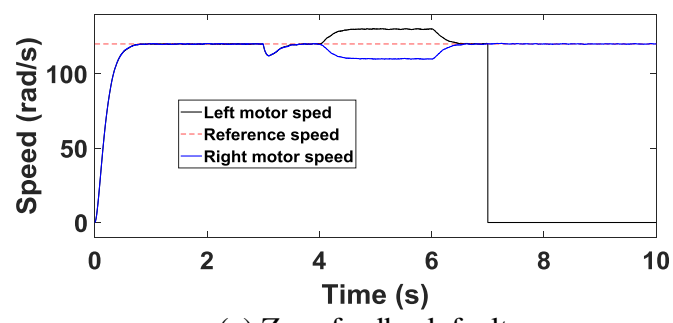

(c) Zero-feedback fault

Fig. 8. Speed-time of PCS-EV by DTC

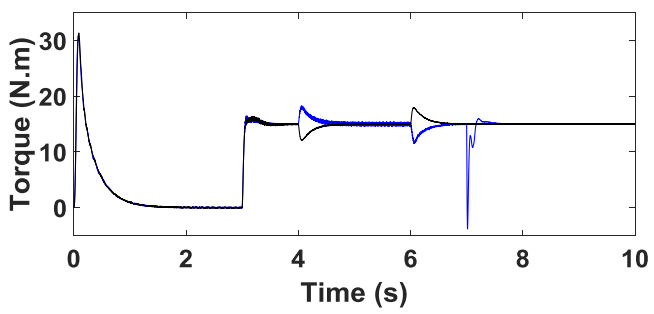

(a) Positive offset fault

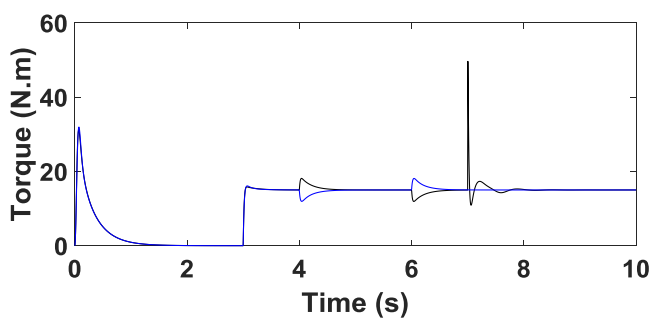

(b) Negative offset fault

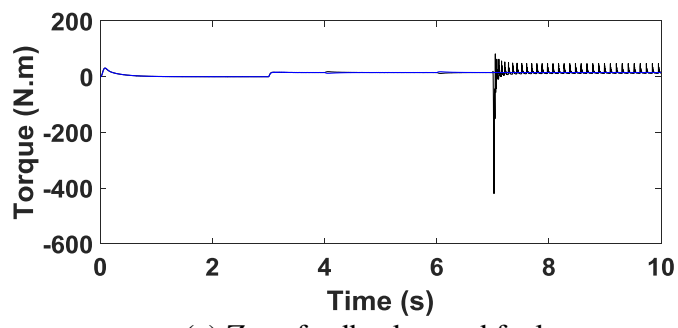

(c) Zero-feedback speed fault

Fig. 9. Torque-time of PCS-EV by FOC

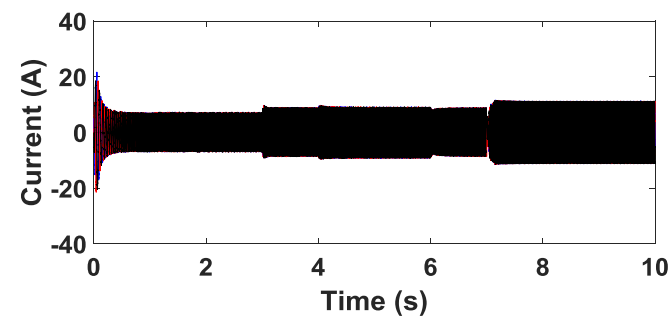

(a) Positive offset fault

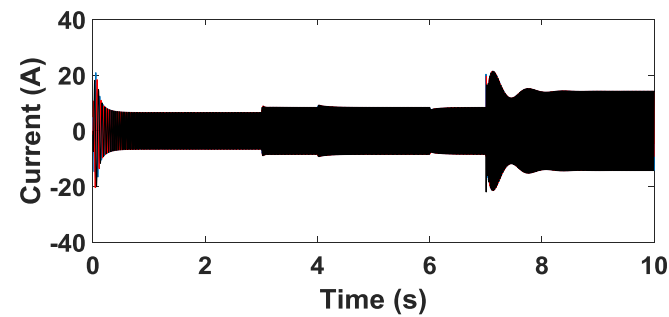

(b) Negative offset fault

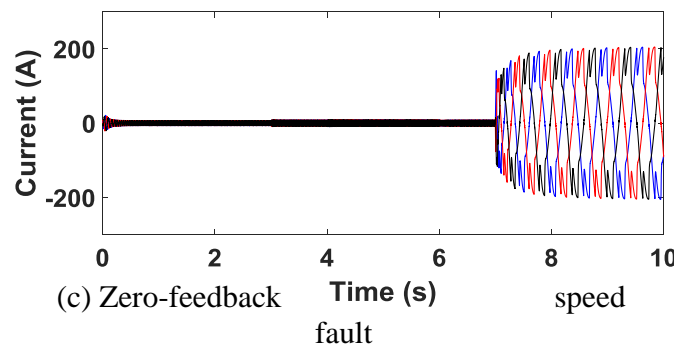

Fig. 11. Stator current-time of PCS-EV by FOC

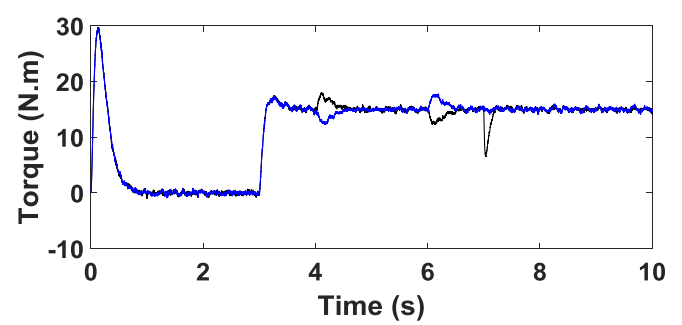

(a) Positive offset fault

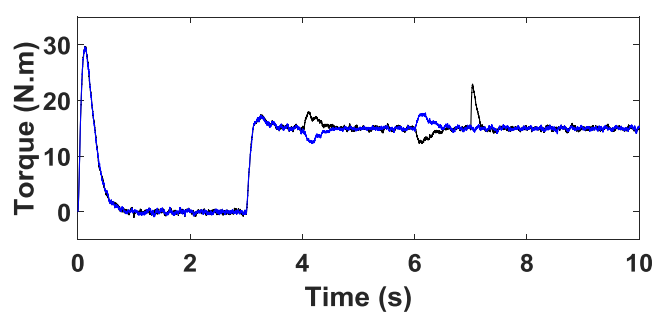

(b) Negative offset fault

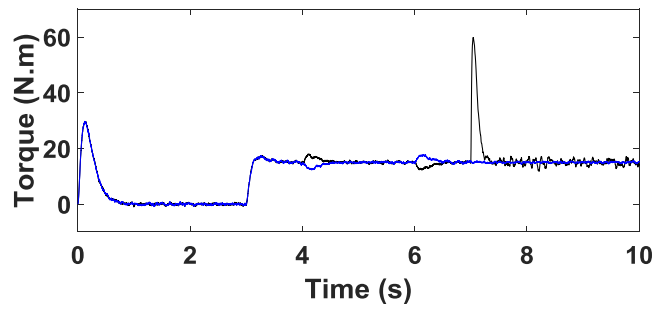

(c) Zero-feedback speed fault

Fig. 10. Torque-time of PCS-EV by DTC

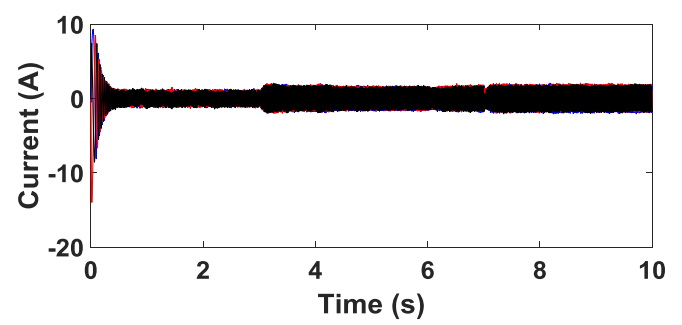

(a) Positive offset fault 


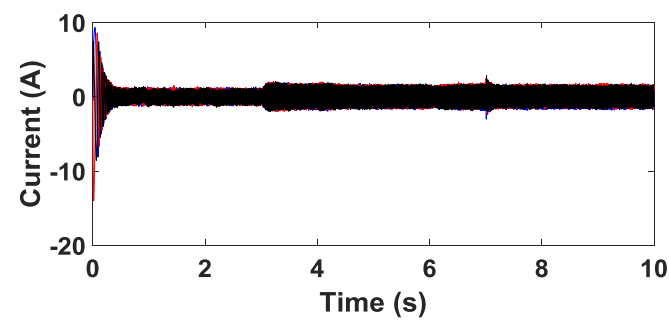

(b) Negative offset fault

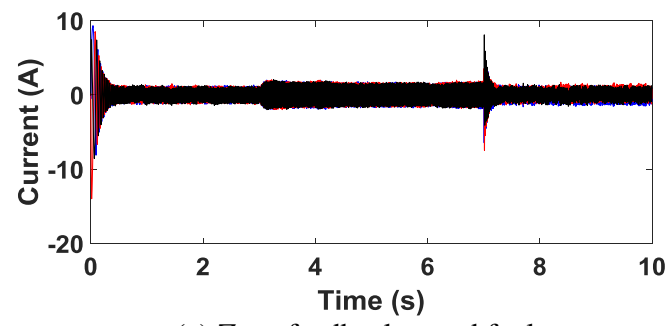

(c) Zero-feedback speed fault

Fig. 12. Stator current-time of PCS-EV by DTC

\section{CONCLUSION}

This paper presents a comparative study between the failures effect caused by the speed sensor faults on the proposed propulsion control system of the electrical vehicle (PCS-EV).

To drive this vehicle, two conventional controls are used. First one is a field-oriented control (FOC) and the second one is a direct torque control (DTC). Two types of speed sensor faults have been occurred on the PCS-EV structure: offset faults according to positive and negative values, and also a zero-feedback fault. The analysis time responses of the simulation tests carried out the PCS-EV show that DTC scheme presents improved control performances than FOC scheme with the presence of the offset faults. In other hand, we can note that the great impact of zero-feedback on the FOC scheme relatively to DTC scheme where the stator current strongly increased in FOC scheme. However, note that in both cases of the control schemes the speed of motor is lost. That's means unfortunately the loss of the systematic control on the electrical vehicle driven by the PCS structure.

\section{Nomenclature}

$\begin{array}{ll}v_{s d}, v_{s q} & \text { Direct and quadrate stator voltages } \\ i_{s d}, i_{s q} & \text { Direct and quadrate stator currents } \\ R_{s}, R_{r} & \text { Stator resistance, rotor resistance } \\ L_{s}, L_{r} & \text { Stator inductance, rotor inductance } \\ M & \text { Mutual inductance } \\ p & \text { Number of pole pairs } \\ \omega_{s} & \text { Synchronous angular speed } \\ \sigma & \text { Leakage factor, } \sigma=1-\frac{M^{2}}{L_{s} L_{r}}\end{array}$

$\phi_{s \alpha}, \phi_{s \beta} \quad$ Stator fluxes components in stationary frame

$\phi_{r d}, \phi_{r q} \quad$ Direct and Quadrate rotor fluxes

$\phi_{r} \quad$ Flux modulus

$\theta_{s} \quad$ Orientation angle

$\Omega \quad$ Mechanical speed

$\Omega_{1}, \Omega_{2} \quad$ Speeds of motor 1 and motor 2
$\Omega_{0}^{*}, \Omega_{\text {diff }}^{*}$ EV speed command, speed difference

J Rotor Inertia

$e_{d}, e_{q} \quad$ Direct, quadrate coupling terms

$T_{r} \quad$ Rotor constant time

$T_{e} \quad$ Electromagnetic torque

$\omega_{s l} \quad$ Slip frequency

PI Proportional Integral controller

$F(s) \quad$ Closed loop transfer functions

$\Omega_{F} \quad$ Speed fault

$\Delta \Omega_{0} \quad$ Speed fault injection

$\tau_{\text {Fault }} \quad$ Short time fault

$j \quad$ Imaginary unit, satisfying $j^{2}=-1$

\section{Appendix}

Table1. Induction Motor parameters

\begin{tabular}{|r|r|}
\hline Parameters & Values \\
\hline Power & $4[\mathrm{~kW}]$ \\
\hline Voltage & $220 / 380 \mathrm{~V}$ \\
\hline Frequency & $50 \mathrm{~Hz}$ \\
\hline + Eventual three-phase boost transformer with ratio $1 / 20$ \\
adapted to voltage battery \\
\hline$R_{s}$ & $1.2[\Omega]$ \\
\hline$R_{r}$ & $1.8[\Omega]$ \\
\hline$L_{s}=L_{r}$ & $0.1564[\mathrm{H}]$ \\
\hline$M$ & $0.15[\mathrm{H}]$ \\
\hline $\mathrm{J}$ & $0.07\left[\mathrm{Kg} \cdot \mathrm{m}^{2}\right]$ \\
\hline$p$ & 2 \\
\hline
\end{tabular}

\section{REFERENCES}

1. Correa FC, Eckert JJ, Silva LC, Santiciolli FM, Costa ES, Giuseppe Dedini F. Study of different electric vehicle propulsion system configuration. IEEE Vehicle power and propulsion Conference. 19-22 oct. 2015. https://doi.org/10.1109/VPPC.2015.7353024

2. Mehrdad Md, Junaid Akhtar Md, Behera RK, ParidaSK. Propulsion system design of electric vehicle. 6th International conference on PESA, 15-17 Dec.2015.

https://doi.org/10.1109/PESA.2015.7398900

3. Xiao-Feng X, Guo-Feng L,Rong-Tai H. A Rotor field oriented vector control system for electric traction application. IEEE proceedings. Mexico, 2000; 1:294299.

https://doi.org/10.1109/ISIE.2000.930529

4. Lufei X, Guangqun N. Research on direct torque control of induction motor based on TMS320LF2407A. Elsevier B.V. Selection and/or Peer-review under responsibility of Garry Lee. 2012:513-519.

https://doi.org/10.1016/j.phpro.2012.03.119

5. Jianguo S, Quanshi C. Research of electric vehicle IM controller based on space vector modulation direct torque control. International Conference on Electrical Machines and Systems, 27-29 Sept., 2005. https://doi.org/10.1109/ICEMS.2005.202825

6. Benoudjit D, Nait-Said N, Nait-Said M-S. Differential speed control of a propulsion system using fractional-order controller. Electromotion Journal. April-June 2007; 14(2):91-98. 
7. HaddounA, Benbouzid MEH, Diallo D, Abdessemed R, GhouiliJ, Srairi K. Design and implementation of an electric differential for traction application. IEEE Vehicle power and propulsion conference.1-3sept, 2010 .

https://doi.org/10.1109/VPPC.2010.5729056

8. Yu Y, Wang Z, Xu D, Zhou T, Xu R. Speed and current sensor fault detection and isolation based on adaptive observers for IM drives. Journal of power Electronics. 2014; 14(5): 967-979.

https://doi.org/10.6113/JPE.2014.14.5.967

9. Najafabadi TA, Salmasi FR, Jabehdar-Maralani P. Detection and isolation of speed- DC-link voltage-, and current-sensor faults based on an adaptive observer in induction-motor drives. IEEE Trans. Ind. Electron. 2011; 58(5): 1662-1672.

https://doi.org/10.1109/TIE.2010.2055775

10. Bouakoura M, Nait-Said N, Nait-Said M-S. Speed sensor faults diagnosis in an induction motor vector controlled drive. Acta Electrotechnica et Informatica. 2017; 17(1): 49-57.

https://doi.org/10.15546/aeei-2017-0007

11. Sepe RB, Morrison C, Miller JM. Fault-tolerant operation of induction motor drives with automatic controller reconfiguration. ASM International Practical failure analysis. 2003; 3(1): 64-70. https://doi.org/10.1007/BF02717411

Received 2020-04-19

Accepted 2020-07-13

Available online 2020-07-14

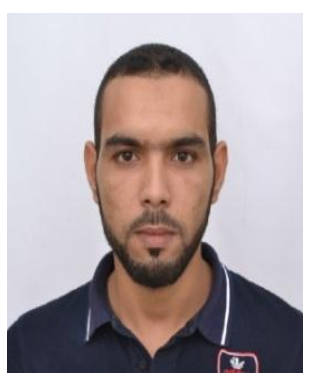

Salah YAHIA CHERIF was born in Batna, Algeria. He received his M.Sc. degree in electric control in 2016 from the University of Batna 2. $\mathrm{He}$ is currently pursuing his Ph.D. studies at the same University. His research theme is the control and diagnosis of electric vehicle dual-induction motor.

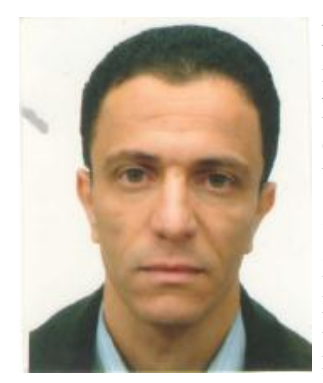

Djamel BENOUDJIT was born in Batna, Algeria. He received his M.Sc. and Ph.D. degrees in electrical engineering from the University of Batna, Algeria, in 2005 and 2010 respectively. In 2015, he joined the Institute of Health and Safety, University of Batna 2. His research interests include power electronics, electrical machines and drives, control system for electric vehicle.

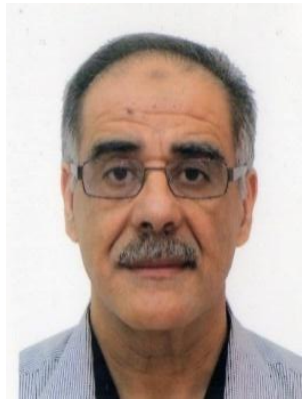

Mohamed-Said NAIT-SAID

was born in Batna, Algeria. He received his M.Sc. in Electrical and Computer Engineering from the Electrical Engineering Institute of Constantine University, Algeria, in 1992. He received his $\mathrm{Ph} . \mathrm{D}$. degree in Electrical and Computer Engineering from the University of Batna in 1999. Currently, he is a Full Professor at the Electrical Engineering Department, University of Batna 2. His research interests include electric machines, drives control and diagnosis.

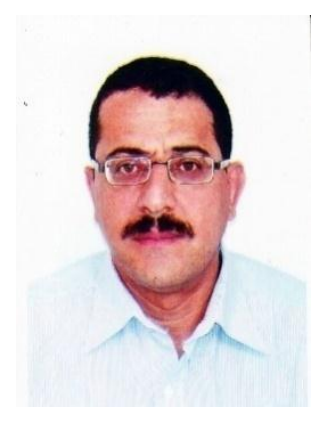

Nasreddine NAIT-SAID was born in Batna, Algeria. $\mathrm{He}$ received his M.Sc. degree in Industrial Electricity in 1993 and Ph.D. degree in electrical engineering from the University of Batna, Algeria in 2003. Currently, he is a Full Professor at the Electrical Engineering Department, University of Batna 2. His research interests include application of AI techniques and control in the field of electrical machines. 